University of Nebraska - Lincoln

DigitalCommons@University of Nebraska - Lincoln

$10-31-2014$

\title{
The Promise of the Digital Humanities and the Contested Nature of Digital Scholarship
}

William G. Thomas III

University of Nebraska-Lincoln, wthomas4@unl.edu

Follow this and additional works at: https://digitalcommons.unl.edu/historyfacpub

Part of the Digital Humanities Commons, and the History Commons

Thomas, William G. III, "The Promise of the Digital Humanities and the Contested Nature of Digital Scholarship" (2014). Faculty Publications, Department of History. 198.

https://digitalcommons.unl.edu/historyfacpub/198

This Article is brought to you for free and open access by the History, Department of at DigitalCommons@University of Nebraska - Lincoln. It has been accepted for inclusion in Faculty Publications, Department of History by an authorized administrator of DigitalCommons@University of Nebraska - Lincoln. 
The Promise of the Digital Humanities and the Contested Nature of Digital Scholarship

William G. Thomas III

October 31, 2014 version

in

A New Companion to Digital Humanities, 2nd Edition

edited by Susan Schreibman, Ray Siemens, John Unsworth

(Wiley-Blackwell, January 2016) 
Whether engaged in history, literary criticism, philosophy, or philology, scholars in the digital humanities have been concerned with reshaping their scholarly activity and their institutional structures for a natively digital world. They have been open to multiple forms of analysis, to sharing sources and materials (data), and to adopting large-scale, distributed models of scholarship. They have proceeded from an important recognition: that we are now in an era of capaciousness, of ubiquitous storage, of networked information, and of unprecedented access. Rather than orienting scholarship around a model of scarce materials, limited access, and expert gate-keeping, the digital humanities at its most vibrant has been about widening the scope of the humanities, opening access to sources, and broadening definitions of scholarly activity.

As an example, in 2011, the University of Nebraska-Lincoln started an experimental project called The History Harvest. Its main objective was to digitize, collect, curate, and interpret family and community history. Every year students, working with expert faculty, select a community to engage with and undertake a "harvest" of family letters, photographs, stories, and objects. In 2012, The History Harvest focused on North Omaha, birthplace of Malcolm X, a jazz hub in the twenties, and a terminal point for much of the Great Migration. The students invited anyone to bring their family records for discussion and digitization. Dozens of North Omaha residents brought their history: church records, military records, jazz records, photographs, and homestead titles. These records were shared, discussed, documented, and digitized.

One individual, Warren Taylor, brought his great-great-grandmother's pewter folding cup that she carried as a slave in the fields. He also brought her penny, an 1840 "Liberty" penny that she carried with her, a symbol of eventual freedom. Both had been passed down for generations in the family.

The animating premise of The History Harvest, like many digital humanities research projects, is that our digital heritage is fundamentally skewed toward government and elite sources. The base research being conducted in The History Harvest is, therefore, aimed at archival first-order work of digital capture, encoding, and sharing. Building a publicly accessible collection, the project can provide a foundation for the generation of future scholarship on a range of subjects, places, and periods. But, like the digital humanities writ large, The History Harvest will reach fruition when the larger community takes advantage of the specifically digital nature of the collection in order to create new forms of historical discovery and argument. Like many other digital projects, the first-order effort at digitization, collection, and assembly of materials serves multiple worthy purposes. If successful, the project might open up digital humanities methods to smaller partnering institutions, sustain a robust hub of scholars, and expose fresh archives for inquiry at multiple scales of analysis. Although promising and opportunistic, such projects should lead ultimately toward digitally native interpretive scholarship.

Yet paradoxically, the twenty-year surge in the digital humanities--from 1993 to 2013-has produced relatively little interpretive or argumentative scholarship. In this first phase of the digital humanities, scholars produced innovative and sophisticated hybrid works of scholarship, blending archives, tools, commentaries, data collections, and visualizations. For the most part in 
the disciplines, however, few of these works have been reviewed or critiqued. Because the disciplines expect interpretation, argument, and criticism, it could be argued that digital humanists have not produced enough digital interpretive scholarship and what we have produced has not been absorbed into the scholarly disciplines.

At the core of this matter of concern lies a two-fold contest over the nature of scholarship. Between the core disciplines and the digital humanities there is a difference in kind over whether digital works constitute scholarship. Within the digital humanities, there is a difference in degree over what constitutes digital scholarship. In the next phase of the digital humanities, the contested nature of this two-fold problem deserves our attention. Scholars might build bridges to the core disciplines in ways that define their works and give shape to digital scholarship. We might ask what forms of scholarly expression and communication are suited to the digital environment and what qualities and properties do digital works possess. What components characterize digital scholarship? What types of data do digital works feature and how are they arranged? What is the nature of their interpretive salience? How do they function?

Rather than explain the self-evident ways that digital scholarship differs from or extends traditional print scholarship, a question I wish to bracket, we might explore the nature of digital scholarship and the variation it takes. In the digital humanities we have experienced two decades of unfettered experimentation in the form of scholarship. Although such experimentation should continue, genres that can be circulated, reviewed, and critiqued would afford colleagues in the disciplines ways to recognize and validate this scholarship. Properly focused but broadly defined, such genres might alter the disciplinary conversation and appear in venues that provide a foundation for future scholarship in the disciplines. In the next phase of the digital humanities, then, scholars have the opportunity to debate, and perhaps clarify, the qualities and characteristics of digital scholarship.

The uncertain and contested nature of digital scholarship can be seen in two recent reports on the state of the humanities in American higher education: Harvard University's "Mapping the Future" report and the American Academy of Arts and Sciences' "The Heart of the Matter" report. Each of these reports made extensive recommendations, but neither the Harvard report nor The Heart of the Matter report explored in detail the impact of the digital humanities on the disciplinary modes of scholarly research and communication. Harvard's report was telling-it included just a single reference to digital humanities in one footnote in its 53-page document. The Heart of the Matter report directly acknowledged "the digital age" but mostly focused on two developments: the rise of open online learning environments and the opportunities that digital projects create for lifelong learning and the preservation of cultural texts and documents.

Citing a handful of digital initiatives, such as The Perseus Digital Library, The Heart of the Matter report offered just one, highly instrumental and deterministic, statement on the possibilities of the digital age: 
Online resources offer unprecedented opportunities for scholars to frame topics of public interest, to participate in a wider community of public intellectuals, and to reach general audiences. The digital world offers vast new possibilities, not only for delivering instruction, but also for facilitating research and for making the past and future possibilities come alive to students of all ages: historic buildings are reconstructed; family trees can be traced; classic texts and manuscripts are made accessible. (Commission on the Humanities \& Social Sciences 2013: 52)

From the beginning of the 1990s, however, as the networked possibilities of The World Wide Web became more and more robust, Edward Ayers, Jerome McGann, and others repeatedly argued that we have the entire human record (cultural, written, spoken, performed) to digitize, organize, prepare, interconnect, analyze, and interpret, and we have the digital capacities (memory, networks, and protocols) to do so in ways we were only beginning to realize. (McGann 1997, 2001; Ayers 1999) The work of digital scholars, therefore, would not be a simple operation of migration of data from analog to digital, as envisioned in The Heart of the Matter report. This effort would be a humanistic scholarly endeavor, a process of assembling, encoding, editing, and interpreting. It would demand us to consider anew how we represent knowledge, and it would require newly trained scholars and practitioners who had fluency in the hardware and software technologies of the digital medium. These digital scholars would attempt unexpected, non-traditional forms of scholarship, and their work would not fit within the wellestablished confines of the monograph or the academic journal. Instead of merely facilitating research, digital technologies would shift the definition of scholarship and digital scholars would invent new modes of interpretive argument and criticism. "A major goal of mature hypertextual history," Ayers wrote in 1999, "will be to embody complexity as well as to describe it." (Ayers 1999)

Many scholars in the digital humanities began to see themselves as, and to act as, an open community of practice, including anyone whose energy, expertise, and enthusiasm aligned with theirs. Rather than to conceive of their project as necessitating a separate discipline or field, digital humanists worked within the disciplines from a loosely defined set of common methods, all concerned with a broad recognition: that humanistic understanding and inquiry was being reconstituted in digital form through digital technologies.

The first twenty years of the digital humanities, then, saw widespread experimentation around three orders of scholarly activity, each building on and in relation to the other, each sometimes pursued within the other:

\section{Reassembling the human record in digital form;}

2. Shaping the affordances of humanistic materials in digital form; and

3. Creating discipline-based interpretive scholarship in digital form. ${ }^{1}$

These scholarly activities could be understood as sequential and yet each could be independently pursued. Scholars built digital archives, layered them with affordances that were premised on interpretive decisions, then wove interpretive scholarship into a digital project. So interwoven were these activities that non-digital scholars could see little that resembled their 
expectations for peer-reviewed scholarship. Meanwhile, digital humanists found few reasons, given the contours of the medium, to approach their work differently. (Waters 2013)

Nearly twenty years later, we might ask how far we have come on each of these three endeavors. By some measures, we have not come very far, especially toward the third. A recent overview of digital innovation in scholarly publication in the humanities found that there were few hypertextual works that embodied complexity or altered the mode of scholarly communication in ways uniquely suited to the online space. Ayers' vision, however appealing, was unfulfilled. Innovation in humanities scholarship, Alan Gross and Joseph Harmon concluded, "has been confined, for the most part to sidestream venues; mainstream publication has yet to be seriously affected." The authors found it "disturbing" that after two decades they had found "so little" Internet-based scholarship in the humanities. And even "more disturbing," the innovative scholarship they did find was mostly marginal to the careers of the scholars who produced it, funded nearly entirely through outside agencies, and produced as special projects, "not routine activities." (Gross and Harmon).

One reason for the lack of progress toward discipline-based interpretive digital scholarship has been the continuous vitality of the monographic culture in the humanities. At least in the discipline of history, the monographic form has continued to serve as the principle means by which the profession communicates. Built on the rigorous review of evidence, argument, and narrative quality, this system has produced stunning examples of creative and exciting scholarship. (Ayers 2013a) In addition, journals often serve as the gatekeeper and record of scholarship in the humanities and social sciences, reviewing and critiquing monographs in addition to publishing scholarly articles that shape the discipline's conceptual, methodological, and theoretical frameworks. Yet most journals do not index, review, refer to, incorporate, imprint, or publish anything created solely for the digital medium. Because digital work is rarely featured or recognized in the leading journals, among other reasons, younger scholars have proven reluctant to develop born-digital scholarship, and departments have had difficulty evaluating this scholarship for promotion and tenure. (Ensign 2010; Howard 2012; Townsend 2010) ${ }^{2}$

These barriers to digital scholarship, however, are only the most visible, and they hide the larger epistemological and heuristic questions. More precisely, the problem we face, according to historian Chiel Van Den Akker, is that "the historical monograph no longer seems an appropriate model for historical understanding in a digital environment." In fact, the digital environment supports, indeed demands, new narrative forms that are more participatory, dialogic, procedural, reciprocal, and spatial. Van Den Akker suggests that the "dialogic process" is "what matters most" and what defines online scholarship. He argues that the process of engagement with the reader distinguishes "online narrativity" from the linear narrative forms found in monographic scholarship. (Van Den Akker 2013: 107, 113)

Similarly, Ann Rigney has pointed out the monograph "can no longer be taken as a given." She notes that "in the new media ecologies ... digitization and the internet offer new technologies for producing and disseminating historical knowledge and, in the process, present both opportunities and challenges." Digital humanists, she argues, have charted a "new theoretical model for viewing historical narrative in terms of its social production by multiple agents across different platforms." (Rigney 2010: 100) 
If the new media ecologies Rigney refers to are indeed naturally "multimodal," then they demand new practices in scholarly production. For Rigney, the result is clear: scholarship will be characterized by "distributed authorship" and undertaken through networks or hubs of scholarly activity. Continuous flows of information and analytical procedures will unfold as scholarship. There will be no fixed final product. (Rigney 2010: 117)

Recently, computer scientist Jaron Lanier has suggested a variety of ways that books, authorship, and readership might change in the digital environment. Worrying that we might lose "the pattern of what a book is in the stream of human life and thought," Lanier predicts that books of the future will be crowdsourced, will be written with the aid of Artificial Intelligence software, and will change between readings or between readers. "Books will be merged with apps, video games, virtual worlds, or whatever other digital format becomes prominent," he argues. (Lanier 2012: 354-357)

As a second-order move, digital scholars have emphasized the need for establishing "affordances" embedded in the digital objects being assembled and digitized for humanistic inquiry and research. Affordances might include encoded metadata, enriched markup, specialized interfaces, geo-spatial and locational encoding, programs for sifting through data, and APIs.

The idea of affordances in the digital humanities has been borrowed from several disciplinary theories. The first is ecological psychology, building on the work of James Gibson, a leading theorist in perception, and the term is worth examining. According to Gibson, an affordance is the particular quality of an object or an environment that allows particular types of action. Affordances are also properties of an object or environment that affect the capabilities of an actor, and in this sense, they are relative to the type of actor. In Gibson's well-known example, the properties of a surface, such as the ground beneath our feet, could be either "stand-on-able," affording support for heavy animals to walk or run upon, or "sink-into-able," affording no such support except for water bugs. The affordances, therefore, are relative to the actor, not just abstract physical properties. Gibson explained, "different layouts afford different behaviors for different animals, and different mechanical encounters." But Gibson also developed the theory of affordances to support his ideas of perception, arguing that affordances cut "across the dichotomy of subjective-objective" and point "both ways, to the environment and to the observer." (Gibson 1979: 127-128)

Second, Human Computer Interface (HCI) theorists, adopted the term after Donald Norman used it in The Psychology of Everyday Things. Norman considered affordances to be user interfaces with properties that were perceptually salient, and in this way his use of the term went beyond Gibson's original theory. He considered affordances to be perceived by the actor and already known and familiar. They were culturally dependent and shaped by the prior experiences of the user. Norman also suggested that an affordance included the way in which the possibilities of the object are made known to, conveyed, or made "visible" to the user. (Norman 1988)

Scholars in digital humanities have loosely applied the term in both the original Gibson formulation and in the HCI derived sense popularized by Norman. Ignoring the substantial 
difference between the two has led to some confusion. Affordances might best be considered properties of digital objects that are relative to the reader rather than uniform. They are not linear or fixed. Indeed, much of the energy and work in the digital humanities community has been framed around building digital objects with particular properties, tools that are inflected in ways specific for humanistic inquiry, interpretive acts, and formulating hypotheses. These efforts have been substantial, and include large-scale digital editing projects, interface design for digital reading, query design, and data encoding. The shaping of affordances has been preparatory to, and vital for, further interpretive scholarship. (Deegan and McCarty: 166)

Janet Murray in Inventing the Medium: Principles of Interaction Design as a Cultural Practice explains how the digital medium exploits certain affordances. Rather than settle for remediation of old media into digital forms, Murray encourages scholars and designers to "think more radically." She describes four essential affordances of the digital medium: procedural, spatial, encyclopedic, and participatory. According to Murray, "these four properties constitute our design space, the context for all of our design choices." Every work of digital scholarship can be assessed on the degree to which it maximizes these four affordances. Some works may be more spatial than participatory or more encyclopedic than procedural. Murray's formulation of an "affordance grid" offers a particularly helpful way to categorize digital works. By placing a digital project on the scale of its relative engagement in each affordance category, Murray suggests we can "map an existing or proposed artifact against the larger design space in order to identify opportunities for growth and to predict the direction of media innovation." Affordance mapping entails asking: "What does it do? What can I (the interactor) do? Where am I in relation to the whole? What are the boundaries of this domain?" (Murray: 45, 51, 91)

But even within digital humanities, we are often vague about what we mean by digital scholarship. Unsurprisingly, given the strong emphasis on digital humanities as solely a methodological approach, some scholars consider the first- and second-order activities listed above to be de facto digital scholarship. Others suggest that any monographs or scholarly journal articles derived from digital modes of inquiry and research also naturally qualify as digital scholarship, even if the final publication of these results takes place in traditional formats and scholarly venues. The former position holds that the digital humanities might undertake tools and methods divorced from the concerns, questions, and understandings in a specific discipline. The latter position appreciates the need for disciplinary grounding but does not recognize the fundamental renegotiation in the form of scholarly communication that the digital medium demands. We might therefore distinguish between second-order and third-order work in the digital humanities and between digitally informed scholarship and digital scholarship.

Edward Ayers recently provided a useful start: digital scholarship is "discipline-based scholarship produced with digital tools and presented in digital form." He has suggested that we need, in fact, to innovate more aggressively and to invest in its creation. "Digital scholarship is the missing part of the cycle of productivity that we have long believed our investments in information technology would bring to institutions of higher education." (Ayers 2013)

Scholarship built on and from digitized sources and presented in digital form would prove appropriate to the digital environment in ways that the monograph no longer satisfies. A robust digital infrastructure for the disciplines used in the service of specific arguments, moreover, would allow the humanities scholar possibly to: 
- amplify an argument within nested modules of evidence and historiography;

- simulate the worlds we are trying to reveal in multiple dimensions;

- embody the full range and complexity of the historical problem;

- reveal simultaneity of time, place, and scales; and

- situate multiple perspectives of historical participants, past scholars, and current readers and collaborators.

Although Ayers' definition of digital scholarship is explicitly "discipline-based," most historians, to take one subset of the digital humanities, have remained bystanders in the broader effort to create digital scholarship at any of the three levels. In a survey of historical scholarship for the period 2003 to 2013, compiling an index of over 1,000 digital history scholarly products (blogs, projects, hypertexts, archives, conference papers, journal articles, and web sites), digital activity skewed heavily toward particular institutions and formats. During this period, the American Historical Association annual meeting hosted 281 conference papers or presentations focused on digital scholarship. The number and variety of these papers were impressive, but over 75 were given at just one conference: the 2012 conference when the president of the association made a concerted effort to showcase digital scholarship. With over 200 scholar-led digital history projects and over 50 student-led digital history projects, the scope of digital history scholarship has expanded measurably in the last decade. Yet, nearly all of these projects were housed in a few centers and institutes where digital history has been nurtured and sustained with institutional and social support (George Mason University, University of Virginia, University of Nebraska, Stanford University). (Thomas and Nash 2013) ${ }^{3}$

In sum, the digital humanities across several disciplines has deferred substantive engagement with the third-order problem of interpretation, narrativity, and argument in digital form. Charitably, digital scholars have been concerned with creating frameworks suitable for interpretive arguments; less charitably, digital scholars have been willfully unconcerned with interpretation, argument, and criticism. While some digital humanists have regarded the firstand second-order assembly of digital resources in itself to be an act of interpretation, scholars in the disciplines by and large have resisted this view. In response, digital scholars might not only endeavor to explain the interpretive affordances they undertake but also formulate agreed upon genres for digital scholarship.

The scholarship of the digital humanities largely resides outside the disciplines, but this precarious situation threatens to render either the disciplines irrelevant to the digital future of cultural communication or the digital humanities irrelevant to the future of the core disciplines in the humanities. If we renew our efforts to imagine genre conventions for something we would call digital scholarship, then we could create forms of scholarly communication so robust and well established that a digital work could become an essential work in the field of history or literary criticism.

In this way the digital humanities holds more promise than yet realized--to broaden its methods into the disciplines, to alter the interpretive models in the disciplines, and to shape more fully the means of disciplinary intervention. Digital humanities scholars have been especially effective at creating hubs of network-enabled scholarly activity and engaging students as 
collaborators. Greg Crane has recently drawn attention to the need for "a new culture of learning" not only for the field of classics, but also more broadly for the humanities. According to Crane, "we need a laboratory culture where student researchers make tangible contributions and conduct significant research." Crane argues, "the crush of data challenges us to realize higher ideals and to create a global, decentralized intellectual community where experts serve the common understanding of humanity." (Crane 2012a; Crane 2012b) Ayers also recently called for students to participate in a cycle of "generative scholarship." He suggested that students build their work alongside ongoing research projects so that their contributions are assessed, validated, and preserved. (Ayers 2013b)

In the training of graduate students, digital humanities might consider a serious effort to classify digital scholarship to provide a rough typology for those both in the field and outside of it, as a set of definitions for genres suitable to our disciplines. Although digital scholarship is often collaborative and blurs the line between archive, tool, and publication, we might search for common forms of scholarly intervention, train students for these genres, and establish categories of digital scholarship for review in the disciplines. For twenty years, digital scholars have called for experimentation in the forms of scholarship, and the results have been exciting. Concentrating on a few forms, at this important juncture, would support systems of review and evaluation, provide clarity for disciplinary structures of scholarly communication, sustain a common framework for graduate training, and encourage scholars to participate in the creation of digital scholarship.

A few forms of digital scholarship have become relatively well defined and commonly pursued across the digital humanities. They are offered here not as a definitive list but as suitable categories for organizing and presenting digital scholarship.

\section{Interactive Scholarly Works (ISWS):}

These works are hybrids of archival materials and tool components, and are situated around a historiographically significant or critical concern. These works often assert a methodological argument as well, demonstrating that the combination of tools and materials serves as a method worthy of applying to the problem. Interactive Scholarly Works have a limited set of relatively homogenous data, and they might include a textual component on the scale of a brief academic journal article. They feature an API for users to access the data and programming directly. Relatively tightly defined in subject, ISWs provide users with a high degree of interactivity in a limited framework. Elijah Meeks and Karl Grossner have recently proposed a definition for these works: "a digital archive . . . a tool for exploring . . . , and an argument about [a subject]. Furthermore, it makes a methodological argument that its representations - its computational model and visualizations - are a useful means for reasoning about [the subject]." (Meeks and Grossner 2012)

Digital Projects or Thematic Research Collections (TRCs): 
Digital projects, sometimes referred to as Thematic Research Collections, are perhaps the most well defined genre in digital humanities scholarship. Carole L. Palmer's 2004 review of these works emphasized several qualities, such as their heterogeneous datatypes, structured but open ended, designed to support research, multi-authored, primary sources. Combining tools and archival materials framed around a historiographically significant or critical problem, these projects are sprawling investigations into a major problem. Typically gathering thousands of objects and records from widely varying institutions and in widely varying formats, digital history projects contain "digital aggregations" of primary sources that support research on a particular theme or historical question. Scholars embed interpretive affordances in the collection and use these affordances to open up new modes of inquiry and/or discovery. They are openended projects and often support ongoing research by multiple scholars or teams. Often traditional peer reviewed scholarship is derived from the thematic research collection. The next phase of thematic research collections might feature interpretive scholarship embedded within and in relationship to the collection. (Palmer, 2004)

\section{Digital Narratives:}

These scholarly works are born-digital, and they primarily feature a work of scholarly interpretation or argument embedded within layers of evidence and citation. They do not and presumably cannot exist in analog fashion. They may be multimodal, multi-authored, and userdirected. They may change between and among readings, either through updates or algorithmic reconstitutions. Unlike the first generation of "eBooks" which transferred analog books into digital formats, these nonlinear, multimodal narratives offer explicit hypertext structures. These works primarily provide multiple points of entry for readers and situate evidence and interpretation in ways that allow readers to unpack the scholarly work. They are highly configured, deeply structured, and strongly interpretive pieces of scholarship. They could be stand alone self-generating web sites, cloud applications, or they could be presented in a mediarich scholarly publishing framework such as Scalar.

Simulations constitute a new form for scholarly research and publication as well. Interpretive decisions are embedded at every level in any simulated, textured environment, and feature a range of media products, including video, audio, and 3D models and game engines. Historical simulations and humanities-oriented games possess varying degrees of interpretive strength. Some are purely representational and feature minimal interpretive or argument-driven analysis. Others offer simulated decision-trees in a game-engine environment with heavily interpretive choices. (Coltrain 2013, McGann and Drucker, 2000) Hybrid media objects that combine text, graphics, live action, and animation sequences also constitute what Lev Manovich calls "a new species" in the digital medium and can be evaluated using Murray's affordance grid as well as the matrix table provided here. (Manovich, 2013) While simulations will likely become in and of themselves a category of digital scholarship with particular characteristics that set them apart from the above types of scholarly work, at this writing they are most commonly used in a supplementary fashion. 
In a landmark 1997 study on the future of narrative, Janet Murray emphasized specific qualities inherent in cyberspace, and we may consider in a similar fashion what qualities characterize the above categories of digital scholarship. (Murray, 1997) Assessing the types of data, components, organization, scope, interpretive nature, and character of digital works allows us to separate one category from another. An ISW, for example, differs from a Thematic Research Collection not only because its scope is more tightly defined, but also because its interpretive nature lies in the query structures it provides the reader rather than in the encoded affordances that a Thematic Research Collection builds into its archival materials. The ISW operates around a series of procedural inquiries, whereas the Thematic Research Collection offers open-ended investigatory structures. These characteristics of the categories are not meant to be exhaustive, but illustrative, and as a basis for categorization and review.

Table 1: Matrix of Digital Scholarship (see attached pdf)

$* * *$

The contested nature of digital scholarship stems in part from an unresolved tension between the digital humanities and the disciplines. Many digital humanists take the position that digital environments demand multimodal, reciprocal, non-linear modes of scholarship. Scholars in the disciplines perceive an inherent contradiction between that form of scholarship and criticism, review, and evaluation. Because criticism has been based on fixity, the fluidity and reciprocity at the heart of the digital environment's affordances suggest that traditional mechanisms of review no longer apply. In other words, if the defining characteristic of digital scholarship is that users make their meanings alongside and in relation to the interpretive framework of the creators, then how do we encourage digital scholars to develop arguments and work critically? More fundamentally, is it possible to conduct scholarly argumentation and conversation in this environment?

In 2004 in The Companion to Digital Humanities, Claire Warwick's essay urged scholars to take "into account the culture of long-established print scholarship" and to consider "a new way to see, and thus to perceive the complexities in the process of interpreting humanities materials." (Warwick 2004) The genres for such scholarship were limited in 2004, but in 2014 they are beginning to take shape. The majority of all humanities activity is already and will continue to take place in the digital environment. ${ }^{4}$ It seems clear that if digital scholars do not shape the future of humanities scholarship online in the open web, then others will. In short, the grand challenge from nearly twenty years ago is still before the digital humanities. Only now, we have the tools and networks to make progress in ways we did not then. Will humanities scholars continue to produce conventional scholarship only to deposit it online? Or will we fulfill the promise of the digital humanities and take advantage of the networks, spaces, and audiences online to create and refine new forms of our scholarship?

Bridging the gap between the digital humanities and the disciplines will require changes to institutional priorities and practices at all levels by all parties, including the digital humanities community. In the next phase of the digital humanities, scholars may be called upon to play a 
more purposeful role in making interpretive arguments, to establish genres of digital scholarship, to engage in meaningful critical review of digital scholarship, and to deal more forcefully and deliberately with the digital divides in our disciplines. ${ }^{5}$

For Further Reading:

Cohen, D.J., Frisch, M., Gallagher, P., et al. (2009) "Interchange: The Promise of Digital History." Journal of American History, 95 (2), pp. 442-51. A conversation on the fluidity of history in digital form and non-linearity of digital scholarship.

Darnton, R. (1999) "The New Age of the Book." New York Review of Books, March 18, 1999 is a pioneering essay on the possibilities of digital scholarship.

Jockers, M. (2013) Macroanalysis: Digital Methods and Literary History. Champaign, IL: University of Illinois Press. A work of predictive digital humanities in the era of "big data."

McGrenere, J., Ho, W. (2000) "Affordances: Clarifying an Evolving Concept." Proceedings of Graphics Interface, 2000 offers a useful clarification of the use of affordance terminology in Human Computer Interface (HCI).

Moretti, F. (2007) Graphs, Maps, Trees: Abstract Models for Literary History. New York: Verso. A work defining "distant reading" and the implications for the digital humanities in the era of big data.

Pressner, T., Schnapp, J., Lunenfeld, P. (2009) "The Digital Humanities Manifesto 2.0," http://www.humanitiesblast.com/manifesto/Manifesto_V2.pdf (last accessed January 2014). A defining statement arguing "Digital Humanities = Big Humanities = Generative Humanities."

Svensson, P. (2010) "The Landscape of Digital Humanities." Digital Humanities Quarterly, 4 (1). A detailed exploration of the typologies of the digital humanities and the types of activities at the center of the digital humanities.

Thomas, W.G., Ayers, E.L. (2003) "The Differences Slavery Made: A Close Analysis of Two American Communities." The American Historical Review (December 2003). A response to Darnton (1999) and a different approach to the qualities of digital scholarship, emphasizing the prismatic.

Van Eijnatten, J., Pieters, T., Verheul, J. (2013) "Big Data for Global History: The Transformative Promise of Digital Humanities." BMGN - Low Countries Historical Review, 128 (4), pp. 55-77 as well as other articles in this special issue provide an excellent example of the possibilities for digitally native interpretive scholarship.

White, R. (2011) Railroaded: The Transcontinentals and the Making of Modern America. New York: W. W. Norton. An example of how enriched scholarship, with accompanying digital 
works on "Shaping the West," http://www.stanford.edu/group/spatialhistory/cgibin/site/project.php?id=997.

\title{
Biographical Note:
}

William G. Thomas III is the Angle Professor in the Humanities and Professor of History at the University of Nebraska-Lincoln and a Faculty Fellow at the Center for Digital Research in the Humanities at Nebraska. He is a co-editor of "The Valley of Shadow" and director of numerous digital projects.

\begin{abstract}
:
Numerous recent reports have addressed the state of the humanities, but none have explored the ways in which the digital humanities have expanded and opened up possibilities in the modes of scholarly production. This essay examines the contested nature of scholarship between the disciplines and the digital humanities and within the digital humanities. It argues that between 1993 and 2013 the digital humanities led a widespread effort to re-purpose the humanities for the digital age, where scholarship would take place not in the traditional formats but in the open digital environment. Despite the accomplishments of this twenty-year surge in the digital humanities, this essay proposes ways to organize, review, and critique digital scholarship.
\end{abstract}

Keywords:

digital scholarship, digital narrative, interactive scholarly work, thematic research collection, argument, interpretation, simulation

\section{References:}

Ayers, E.L. (1999) "The Pasts and Futures of Digital History," http://www.vcdh.virginia.edu/PastsFutures.html (last accessed January 2014).

Ayers, E.L. (2013a) "Does Digital Scholarship Have a Future?" EDUCAUSE Review, 48 (4), pp. 24-34.

Ayers, E.L. (2013b) "A More Radical Online Revolution." The Chronicle Review, February 4, 2013.

Coltrain, J. (2013) "A 3D Common Ground: Bringing Humanities Data Together inside Online Game Engines," Short Paper presented at Digital Humanities 2013, http://dh2013.unl.edu/abstracts/ab-420.html (last accessed January 2014). 
Crane, G. (2012a) "The Humanities in the Digital Age." Paper presented at "Big Data \& Uncertainty in the Humanities," University of Kansas, http://www.youtube.com/watch?v=sVdOaYgU7qA (last accessed January 2014).

Crane, G. (2012b) "Greek, Latin and a global dialogue among civilizations." Paper in possession of the author.

Deegan, M., McCarty, W. (2012) Collaborative Research in the Digital Humanities. Farnam, UK: Ashgate.

Ensign, R. (2010) "Historians Are Interested in Digital Scholarship But Lack Outlets." Chronicle of Higher Education, Wired Campus Blog, October 5, 2010, http://chronicle.com/blogs/wiredcampus/historians-are-interested-in-digital-scholarship-but-lackoutlets/27457 (last accessed January 2014).

Gibson, J. (1979) The Ecological Approach to Visual Perception. Boston: Houghton Mifflin.

Gross, A., Harmon, J. (forthcoming) The Future Is Already Here: The Internet Revolution in Science and Scholarship. Manuscript shared with the author, May 2013.

Howard, J. (2012) "Historians Reflect on Forces Reshaping Their Profession." Chronicle of Higher Education, January 8, 2012, http://chronicle.com/article/Historians-Reflect-onForces/130262 (last accessed January 2014).

Manovich, Lev. (2012) Software Takes Command. (New York: Bloomsbury Academic).

McGann, J. (1997) "Imagining What You Don't Know: The Theoretical Goals of the Rossetti Archive," Institute for Advanced Technology in the Humanities, http://www2.iath.virginia.edu/jjm2f/old/chum.html (last accessed January 2014).

McGann, J. and Drucker, J. (2000) "The Ivanhoe Game: An Introduction," Institute for Advanced Technology in the Humanities, http://www2.iath.virginia.edu/jjm2f/old/IGamehtm.html (last accessed January 2014).

McGann, J. (2001) Radiant Textuality: Literature after the World Wide Web (New York: Palgrave).

Meeks, E. and K. Grossner (2012) "ORBIS: An Interactive Scholarly Work on the Roman World." Journal of Digital Humanities, 1 (3), http://journalofdigitalhumanities.org/1-3/orbis-aninteractive-scholarly-work-on-the-roman-world-by-elijah-meeks-and-karl-grossner/ (last accessed January 2014).

Murray, J. (1997) Hamlet on the Holodeck: The Future of Narrative in Cyberspace (New York: Free Press) 
Murray, J. (2012) Inventing the Medium: Principles of Interaction Design as a Cultural Practice (Cambridge: The MIT Press)

Lanier, J. (2012) Who Owns the Future? New York: Simon \& Schuster.

Norman, D. (1988) The Psychology of Everyday Things. New York: Basic Books.

Palmer, C. (2004) "Thematic Research Collections." In S. Schreibman, R. Siemens, J. Unsworth (eds.), A Companion to Digital Humanities. Oxford: Blackwell. http://www.digitalhumanities.org/companion/ (last accessed January 2014).

Rigney, A. (2010) "When the Monograph is no Longer the Medium: Historical Narrative in the Online Age," History and Theory, Theme Issue 49 (December), 100-117.

Thomas, W.G., Nash, K. (2013) DigitalHistory Zotero Library, http://www.zotero.org/groups/digitalhistory (last accessed January 2014).

Townsend, R.B. (2010) “How Is New Media Reshaping the Work of Historians?" Perspectives on History, November 2010.

Van Den Akker, C. (2013) "History as Dialogue: On Online Narrativity." BMGN - Low Countries Historical Review, 128 (4), pp. 103-117.

Warwick, C. (2004) "Print Scholarship and Digital Resources." In S. Schreibman, R. Siemens, J. Unsworth (eds.), A Companion to Digital Humanities. Oxford: Blackwell.

http://www.digitalhumanities.org/companion/ (last accessed January 2014).

Waters, D. (2013) "An Overview of the Digital Humanities." Research Library Issues (284), pp. 3-11.

\footnotetext{
${ }^{1}$ The recent controversies at the Modern Language Association over "who's in and who's out" of digital humanities and the arguments over whether coding is a necessary characteristic of digital humanists have led to numerous efforts to define digital humanities as a field. As defined here, "building" broadly includes both editing and encoding, as well as in some cases, programming. The emphasis here is less on programming as a requirement and more on building digital infrastructures that allow interpretive modes of scholarship.

2 Indeed, Robert Townsend's 2010 survey of AHA members regarding research and teaching found that nearly half of those polled had considered publishing online, and valued digital publication as a means to reach a wider audience of historians and get their work out more quickly. He also found that those who have not yet published in an online journal, but would consider it, overwhelmingly cited the perception that online scholarship lacks the scholarly recognition and prestige of print publication as the main reason for their reluctance. (Townsend 2010)

3 The Zotero library, available under the group "DigitalHistory" (http://www.zotero.org/groups/digitalhistory), includes digital history-related projects, tools, essays, and
} 
blogs which we located by systematically surveying the websites of various digital history and humanities centers, university history departments, classroom syllabi, and conducting Google searches for "digital history", "student projects," and variations thereof. We also consulted the CHNM Compendium of Digital Humanities for items relating to digital history. In addition, we have documented 281 papers, panels, and sessions related to digital history presented at the AHA from 2003-2013. This list was compiled by reading through the online programs for the aforementioned years and making note of the topic and affiliation of the speaker, sessions, or panels. Many scholarly associations, including the Organization of American Historians, do not keep past conference bulletins online, or do so only with titles. We used the AHA not only because it is the largest conference, but also because the AHA's web site includes full title and abstract information for each paper, thus producing the most accurate data.

${ }^{4}$ An indicator of the extent of humanities research activity online is Wikipedia, a collective effort that began in 2003. Page views in Wikipedia climbed to over 200 billion in 2012 worldwide. Over 100,000 new articles are created each day. Wikipedians made over 2 billion edits to the site in 2012. The Library of Congress' Chronicling America (chroniclingamerica.loc.gov) alone had over 30 million page views in 2012. Between 2000 and 2006 (the only years for which data are available), the Library of Congress' American Memory (memory.loc.gov) page views rose from 228 million to 996 million. See The Annual Reports of the Librarian of Congress, http://www.loc.gov/about/reports/annualreports/ (last accessed January 2014).

${ }^{5}$ The Council of Library and Information Resources (CLIR) has provided essential leadership in calling attention to the need for broader investment in digital scholarship. The Digital Public Library of America (DPLA) has begun to focus national attention on the problem of digital preservation and access. 